\title{
El Cantar de los Cantares, más valioso que el universo. Realismo poético, hermenéutica y analogía en la lectura del Cantar de los Cantares
}

\author{
Ricardo F. Blanco Beledo
}

Se realiza una somera revisión de algunos elementos que remiten al abordaje hermenéutico para establecer una articulación entre exégesis tradicional y contemporánea sobre el Cantar de los Cantares. Se plantea la pertinencia de la hermenéutica analógica para realizar este tipo de trabajo de investigación en textos bíblicos. El Deseo desde un punto de vista psicoanalítico se muestra como eje conductor del texto del Cantar de los Cantares.

Palabras clave: Cantar de los Cantares, hermenéutica analógica, deseo, psicoanálisis.

A superficial overview of some elements which refer us to the hermeneutic approach was made in order to establish an articulation between the traditional and the contemporary exegesis of the Song of Songs. The pertinence of the analogical hermeneutics is suggested for this kind of work on biblical texts. Desire, from a psychoanalytic point of view, is shown as a directive axis in the text from the Song of Songs.

KEY WORDS: Song of Songs, analogical hermeneutics, desire, psychoanalysis.

Fecha de recepción: 17 de noviembre de 2009.

Fecha de aceptación: 25 de mayo de 2010. 

Ricardo F. Blanco Beledo

Facultad de Filosofía y Letras

Universidad Nacional Autónoma de México

\section{El Cantar de los Cantares, más valioso que el universo. Realismo poético, hermenéutica y analogía en la lectura del Cantar de los Cantares}

El Šir ha širim (El Cantar de los Cantares); más valioso que el universo.

Dijo Rabí ( dante ó distinguido) Akiba, cuando se cuestionó la presencia del Cantar de los Cantares en el Canon de la Escritura: "El mundo entero no vale tanto como el día en que se le dio a Israel el Cantar de los Cantares". ¿Por qué el mundo entero no vale tanto como la recepción de este poema? Contesta Rabí Akiba; "Porque todos los Escritos son santos, pero el Cantar es el Santo de los Santos".

Valle, Mišna, Tratado Yadayim 3,5; 1422

El Cantar es el Santo de los Santos. ¿Qué es el Santo de los Santos; el centro del Templo recientemente destruido, donde se hacía presente la divinidad? ¿Quién es el Santo de los Santos, el mismo YHWH (Tetragrama del nombre de D-s, impronunciable), Elohim (el Señor, se prefiere este nombre en la lectura de la Sagrada Escritura), D-s (se prefiere este grafismo para no 
usar el de "Dios" en la escritura contemporánea)? ¿Debemos concluir que este texto es el mismísimo Revelador, Creador, Señor de señores? ¿Será por eso que no se lo nombra ni una sola vez en el Cantar, porque sería redundante? ¿Será que este canto de enamorados, desplegado desde la corporalidad más sensual y erótica, devela y enmascara, manifiesta y sugiere el Rostro y la Presencia terrena del Santo de los Santos?

Ciento diecisiete versos de amor; un modo de decir que "ninguna cosa es más propia a Dios que el amor". En un mundo de sensaciones corporales, gustativas, dérmicas, auditivas, visuales, vegetales, animales, se expande el anhelo del deseo insatisfecho por esperado o por ya vivido. Carencia, falta, pérdida, desgarramiento, encuentros y seis consumaciones del amor (2: 6, 2:16, 5:3-5, 6:3, 7:12-14, 8:3) (De la Torre, El Amor, 10).

En este régimen actual de la existencia humana, el verdadero amor no puede vivirse más que en esta tensión que acaba con los sueños de plenitud inmóvil, pero que relanza el deseo y lo hace crecer empujándolo tras los pasos del amado (Pelletier, $E l$ Cantar, 18).

¿Son, entonces, los amantes del Cantar y sus requiebros, el Santo de los Santos (Modo de referirse a D-s)?

Por sobreabundancia de sentido, el texto permite los diversos modos de interpretación que ha tenido a través de la historia, seguramente los modelos interpretativos ya utilizados y muchos otros más. Sí, es un canto erótico que se agota en la plenitud del vínculo interpersonal; sí, es también la alianza conyugal de YHWH e Israel, de Cristo y su Iglesia, del místico y su Dios, de dos que se hacen uno en la dinámica histórica de encuentros y desencuentros; este Absoluto Divino, Personal intencional y amante, no es fácilmente aprehensible desde los esquemas mentales de griegos y latinos.

${ }^{1}$ Solamente un apócope en 8:7, "Yah". 
El pensamiento hebreo inventó la historia, rompió con el principio de muerte oculto en las repeticiones inevitables del Eterno Retorno ${ }^{2}$ o de una divinidad impersonal, atemporal e inmóvil. Lo Absoluto Divino es en el devenir del amor y el desamor.

Kadosh (Sagrado)

"Nature est un temple ou des vivants piliers laissent parfois sortir des confuses paroles"; ${ }^{3}$ pocas veces un poema ha expresado con tal claridad lo que constituye el escenario, el telón de fondo del Cantar de los Cantares. La más pura sensibilidad para detectar lo simbólico teofánico en la sensualidad, en la corporeidad perceptora de la naturaleza y en los cuerpos de los amantes.

El cuerpo, propio y ajeno, no es nuestro ser biológico al modo occidental de sabernos pobre y limitadamente maniqueos, estoicos, gnósticos, cientificistas. El cuerpo y la naturaleza son oportunidad, puerta que se abre al viejo y nuevo espacio de la divinidad encarnada, imagen y semejanza del Otro. El Cantar es, para el cristianismo, preanuncio de la Encarnación del Cristo.

El cuerpo humano es naturaleza inspirada, cuerpo parlante, y desde esos registros puede, por tanto, captar al Trascendente desde la / su propia inmanencia.

Lo sagrado (kadosh) a que se refería Rabí Akiba está presente aquí y ahora en la recuperación del paraíso (pardes, jardín de delicias) gracias al amor humano corporal, sensual, erótico, espiritual; recuperador de la unidad del pobre, carente, necesitado y fragmentado ser humano eyectado, expulsado, de la armonía original-posible gracias al redentor vínculo amoroso.

${ }^{2}$ Mircea Eliade afirma que la originalidad de la Religión de Israel es precisamente esta, inaugurar una historia no atada a los ciclos del Eterno Retorno.

3 "La naturaleza es un templo de pilares vivientes que, a veces, dejan salir palabras confusas" (Baudelaire, "Correspondences"). 
Es la corporalidad anhelante, pasional, alerta a olores, sabores, colores, texturas que explota como la exhuberancia de la vida la epifanía de "Yah" (jamás se dice YHWH, el término completo); para qué, si el amor de la pareja es el mismo YHWH...

Recordando la reflexión psicoanalítica, no podía ser otro, más que un judío educado, crecido en el ambiente de la antropología hebrea, quien como Freud pudiera descubrir el secreto de la histeria, enfermedad del sujeto sufriente por palabras atrapadas, literalmente, en el cuerpo. Lo opuesto al texto en consideración.

Se habían perdido las claves del misterio de la histeria, de la neurosis obsesiva, de la psicopatología gracias a los enfoques biologistas-mecanicistas, a los abordajes negadores de la realidad simbólica del cuerpo humano, y por ende a la inmanencia de la divinidad. Solamente alguien que supiera de antemano, gracias a su educación Talmúdica (התלמוד es una amplia obra que recoge principalmente las discusiones de los maestros rabinos sobre las leyes judías, las tradiciones, costumbres, etc.), que el cuerpo humano era una realidad simbólica, locuente, podía recuperar el secreto.

El ser humano no responde a una "ley natural", si entendemos por esta una reducción a las explicaciones positivistas de la "naturaleza". Lo "natural" del ser humano es su crecimiento de sentido más allá de las posibilidades de la ciencia empírica: lo "natural" humano es esta posibilidad teofánica en el vínculo amoroso.

Desde lo humano, efectivamente "Nature est un temple", y el Cantar lo testimonia.

\section{Comentarios, Alegorías y Tipologías}

Algunos han pretendido leer una dimensión conyugal en el texto. Piadosa lectura; jamás el texto da pie para suponer una relación de este tipo en el sentido institucional. El amor humano 
aquí expresado trasciende la Ley. Avance impresionante desde la misma tradición judía hacia la libertad de los hijos de Dios, que continuará desarrollándose tanto en textos sapienciales como proféticos y será re-expresado con claridad por un Pablo de Tarso en I Cor 13; en citas apreciadas por Freud (Pfrimmer, Freud lecteur).

Por supuesto que son valiosas y adecuadas, aunque parciales, las interpretaciones alegóricas y tipológicas del Cantar de los Cantares. Las expresiones del amor puestas en boca y gestos de los actores trascienden a los individuos y pueden ser analogables para una expresión de la relación entre YHWH e Israel gracias a la alianza amorosa establecida, o el modo paulino de comprender las nupcias de Cristo y su Iglesia.

Es un lenguaje de enamorados que reconocen los amantes, sean místicos individuales o comunidades gozosas de su relación corporativa con el Otro, divino y personal, inmanente y trascendente.

El Cantar de los Cantares parece que jamás será lugar de experiencia compartible para timoratos o legalistas. Hemos de reconocer la existencia de un grupo importante de insinceros que aplauden en el vacío porque así se los ordena su Comunidad o Iglesia, pero que en lo personal están desgarrados; no pueden con el sufrimiento de una vida angustiada, el silencio de Dios o el peso de las culpas personales. Aunque saben que ya están de antemano reconciliados, redimidos, perdonados, resucitados y revitalizados en la creación, el narcisismo impide, genera idolatría y se antepone a este tipo de experiencia. Desde ese lugar jamás se entenderá este poema aunque lo reciten de memoria.

Escribe Daniel Lys: "De hecho si el Cantar no estuviera en el canon (de la Biblia), nadie pensaría en darle un carácter alegórico, sino que lo tomaría por lo que es" (Pelletier, El Cantar, 32). 
De los conceptos y los signos

Siguiendo a De la Torre Guerrero podemos afirmar que en la descripción de los amantes y de su relación se utilizan:

-Signos botánicos (como mirra, ciprés, granada, bálsamo, lirio, racimo de uvas, trigo, viña jardín, manzano, palmera, racimo de palmera, cedro, etc.).

-Signos zoológicos (como gamo, cervatillo, rebaño de cabras, palomas, miel de abeja, etc.),

-Signos caseros (como cinta, collares, capa, licor, columna, torre, etc.). Vale la pena hacer el esfuerzo de comprender qué hay detrás de cada signo. El israelita, en el Cantar, hizo el viaje del concepto al signo. A nosotros nos corresponde hacer el viaje al revés: del signo al concepto.

Así se descubre:

Que detrás de una paloma se esconde candor o ternura, o delicadeza, o timidez...

que detrás de un trigal está la vida y la protección que oculta y le da misterio al vientre femenino...

que detrás de una alberca hay trasparencia o frescura, o paz de una mirada...

que detrás de un rebaño hay blancura u orden, o igualdad de unos dientes...

que detrás de una torre hay fortaleza o defensa, o autonomía, o dignidad de la sexualidad femenina...

que detrás de una cría de gacela está la suavidad, blandura o uniformidad de los senos femeninos...

que detrás de un racimo de uvas está la dulzura, la exuberancia o la armonía de los pechos de una mujer...

que detrás de una azucena hay apertura o profundidad sexual femenina...

que detrás de los semicírculos armónicos de un collar están las caderas de una mujer... (De la Torre Guerrero, El Amor, 8). 
En cuanto a la presencia de la metáfora, De la Torre Guerrero afirma:

La metáfora, basada en el signo, ha tenido la osadía de hacernos decir de ciertas cosas lo que éstas en sí mismas nunca poseen. Este atrevimiento rompe con las convenciones que tenemos de los seres y abre nuevas posibilidades de ver con mayor riqueza a cada ser. Y de esta forma cada ser queda tan enriquecido, que casi es otro ser. Sin embargo, en todo este proceso la metáfora no supera el campo literario, ya que afirma de un tercero lo que pertenece a otro, pero el propio mundo de quien habla o escribe no queda comprometido. Esto es lo que hace que se piense en algo más allá de la metáfora, en algo en lo que se supere el campo literario y se comprometa el campo existencial de quien habla. Esto nos obliga a dar un paso más.

Cuando el ser humano trata de revelar su propia interioridad y sus experiencias espirituales mayores, supera el mundo de la comunicación corriente y tiene que echar mano de algo más que la metáfora. Es cierto que puede servirse de ella lo mismo que de cualquier signo y de cualquier género literario, sea el que sea. Lo literario le sirve al símbolo de medio de expresión o de vehículo para poder comunicar esa experiencia vital que está en el interior de la persona. Entonces, en un acto exclusivamente humano, el interesado junta la expresión literaria con su experiencia personal profunda y crea entonces el símbolo. El signo, la metáfora o cualquier género literario narrativo quedan entonces no sólo superados, sino recreados, ya que aparecen cargados de experiencia humana. Por lo mismo, si el lector no puede o no sabe llegar hasta el símbolo, las narraciones bíblicas quedan a mitad de camino, no alcanzan a revelar toda su riqueza de contenido. Todo esto ocurre con el Cantar de los Cantares (9). 


\section{Totalidad y mística}

En el Zohar ${ }^{4}$ se dice que el Cantar de los Cantares es el resumen de toda la santa escritura, de toda la obra de la creación..., el resumen del misterio del Nombre Sagrado y supremo. Este cántico encierra todo lo que existe y lo que existirá; todos los sucesos que ocurran en el séptimo milenio, que es el Sabbat del Señor, están resumidos en el Cantar de los Cantares.

Si miramos por una doctrina abarcadora del pensamiento bíblico debemos olvidarnos de esperar encontrar una teoría sistematizada; la encontramos en un poema de amor, del amor de una pareja. Por eso, este texto es el predilecto de los místicos y el dolor de cabeza de los físicos y metafísicos tradicionales.

Para los Padres de la Iglesia, el Cantar era el texto que mejor catequizaba para el acceso a los Sacramentos (Misterios, en la Iglesia Oriental); se proponía la analogía entre el amante y la amante como los dos términos del hecho sacramental, se pedía al cristiano que se acercara al Otro divino en el Sacramento como lo hacían los amantes del Cantar.

Ambrosio, Juan Crisóstomo, Orígenes, Gregorio Magno, Gregorio de Niza en sus escritos son unánimes en reconocer a este lenguaje como el más adecuado para expresarse en términos de la relación amorosa de los hombres entre sí y con la divinidad.

\section{Hermenéutica, analogía y realismo poético}

No hay ciencia humana que pueda otorgarse el privilegio de hablar de la experiencia humana total. Eso queda reservado al lenguaje de la poesía mística, lenguaje que es icono, que integra y trasciende niveles de unificación humana. Lenguaje icó-

זהד 4 , "esplendor"; es, para muchos, el libro central de la corriente cabalística en el judaísmo; quizás del s. II. 
nico, como el del Cantar, lectura válida en todos y cada uno de los registros de referencia simbólica, polisemia en acción.

La hermenéutica analógica, en particular, parece ser un medio para resolver, o aportar a la resolución de las aporías con las que se encuentran las posturas más habituales en el campo de las interpretaciones bíblicas. Esto es, una tendencia a la búsqueda de soluciones únicas o a la dispersión incontrolada de las interpretaciones.

El llamado principio de analogía modula las afirmaciones al ofrecer al mismo tiempo un reconocimiento del referente bíblico y la posibilidad de predicación tanto desde / para, la similitud cuanto desde / para las diferencias, incluso privilegiando las diferencias.

El enmascaramiento dentro de límites pre-fijados del discurso alcanza un tono de proporcionalidad básica que remite al acceso del decir sobre el fragmento, en cuanto a la sospecha de un posible todo, que no desdeña la posibilidad de un marco ontológico débil pero suficiente.

No se pretende "comprender" unívocamente, ni tampoco negarse a "comprender" absolutamente cayendo en el marasmo de la imposibilidad misma de locución acerca de algo. La hermenéutica analógica permite decir y callar, acceder y limitarse, balbucir cuasi comprendiendo sin creer que tiene la unicidad del saber, y al mismo tiempo abrirse aproximadamente a un amplísimo mundo de abordajes evitando caer en la mudez del discurso a que la llevaría un infinito de interpretaciones sin límite.

Dado el modelo de la poesía simbolista, recordamos que se dijo que era una estética metafísica, porque solía buscar algo trascendente. Para Baudelaire, todas las cosas eran símbolos, esto es, no agotaban su ser en su corporeidad, es más, no tenían existencia física por derecho propio, sino para manifestar la Idea.

El poeta está investido del poder casi mágico de deducir y de precisar el sentido de este simbolismo universal. Más aún, co- 
noce la génesis de su creación. Ve en ella, gracias a una intuición de iluminado, los elementos que surgen de una especie de boca de sombra que tal vez sea el Absoluto, tal vez la Nada. Ante sus ojos atentos se eleva, de no sabe qué insondable abismo, el mundo cambiante de las apariencias (Schmidt, La literatura simbolista, 7-8).

El poeta simbolista, analogable al redactor final del Cantar de los Cantares, trata de superar lo aparente hacia lo profundo, tal vez abismal y en este caso la presencia del Santo de los Santos en la vida del ser humano.

El símbolo, como toda analogía, es a la vez apertura y límite que cierra:

Por lo tanto, es, al mismo tiempo, el instrumento de la visión metafísica del poeta y el límite de esta visión. Para lanzarse a lo absoluto, para refugiarse en él, como el místico en el seno de su dios, sería necesario que el poeta renuncie al poema, se calle, abra la Ventana, rompa el Espejo, destroce el Vidrio. Pero no se atreve a llevar a cabo este acto horrible porque, ligado a pesar de todo a las apariencias, no está seguro de encontrar todavía algo cuando, para tomar un impulso que tal vez sea quimérico, haya suprimido a todas las criaturas de su genio (9).

Se contenta con pulir el Cristal, con rastrear el Absoluto, con eludir la Nada. Hace patente al Señor en la humanidad deseante.

El poeta simbolista se consagraba a su Obra, como un alquimista fabrica un mundo entre el Absoluto y la Nada, y se siente con derecho a destruir sus criaturas. Siempre rozando la oscuridad, como se ve en lo oscuro de sus últimos poemas. Baudelaire, Mallarmé, Rimbaud, todos pretendieron escribir el Poema.

El poema es un dictado del alma que tiene su elocuencia propia, de la que conoce los fines y las reglas, un dictado del alma que da al escritor, no palabras justas, no términos propios, sino una 
especie de palabra perpetua cuyos vocablos son particularmente conmovedores, ya que expresan con impertinente lucidez esas realidades invisibles de las que nuestra persona visible sólo es la apariencia superficial y muy a menudo desabrida (17).

Algunos otros poetas se refirieron a esta búsqueda, como Juan Ramón Jiménez y Borges. Se buscaba el Poema, del que, por supuesto, solo se alcanzaban aproximaciones y participaciones. ¿Será este el caso?, ¿El Šir ha širim será el Poema?

Entre los simbolistas europeos resalta "Baudelaire, grande por haber encontrado la ley cardinal de la Analogía Universal" (28). La analogía les servía para subir a lo alto: "Pero de todas formas los simbolistas, como Mallarmé, aunque con un ardor indiscreto que hace sonreír, asignan a la poesía la siguiente tarea metafísica o mística suprema: la revelación de la Verdad" (31). Por eso, el poeta era una especie de mago, profeta y sacerdote. En el Cantar: Rey, Profeta, Sacerdote, en síntesis el ser humano planeado en la Creación, Imagen y Semejanza, "Él”.

[El simbolista] desdeña con derecho la inteligencia de sus lectores, no ignora que, mal acostumbrados a las precisiones de la Escuela, no están adiestrados en el bello arte de distinguir el Símbolo, que presenta una realidad metafísica difícilmente perceptible, y la alegoría o el emblema, que representa una realidad moral fácilmente concebible.

El Símbolo sólo es oscuro por participar de las tinieblas de las realidades hacia las cuales encamina la meditación. Pero la alegoría puede ser oscura por sí misma, si el poeta o el pintor que la traza la adorna con atributos demasiado rebuscados, como atestiguan ciertas representaciones alegóricas del siglo XV (37).

De ahí la insistencia en que se tuviera una lectura de los poemas que no fuera literal. Mucho antes del siglo Xv esta escucha es esencial para el Cantar. 
Una hermenéutica analógica del realismo poético buscará una lectura no puramente literal, pero tampoco puramente alegórica; en esa mediación reside precisamente la lectura analógica, simbólica, o icónica, que no tiene la pretensión literalista, pero tampoco la deriva alegorista. Se pone en el medio, participa de ambas, y de lo mejor de las dos saca su propia riqueza.

La poética de los simbolistas hace que se reúnan, en el límite, poesía, ética y ontología:

En adelante la poesía tiende a convertirse en una ética o en no sé qué instrumento irregular de conocimiento metafísico, le inquieta la necesidad de "cambiar la vida", como quería Rimbaud, de cambiar al hombre haciéndole tocar lo más hondo del ser (Raymond, De Baudelaire, 9).

La parte metafísica se da con respecto al mundo natural: "Baudelaire adopta frente a la naturaleza exterior una actitud sumamente notable. Ve en ella, no una realidad existente por ella misma y para ella misma, sino un inmenso depósito de analogías y también una especie de excitante para la imaginación" (17). Siempre una ontología poética, imaginativa y basada en la analogía, una ontología analógica. La naturaleza es un bosque de símbolos a interpretar.

La hermenéutica ayuda al hacer de la ontología. La ontología adquiere el carácter de magia y de profecía: "Por tanto, la tarea del poeta, de acuerdo con el sentido adivinatorio que hay en él, consiste en percibir analogías, correspondencias, que adoptan el aspecto literario de la metáfora, del símbolo, de la comparación o de la alegoría" (19). El símbolo conecta al poeta con la realidad completa del universo, tanto lo material como lo espiritual; y es aquí donde nos brinca la imagen del hombre como microcosmos.

Raymond se lo tribuye al alma, aquí sabemos que compete al todo del Basar, Nefesh y Ruach. Decía Raymond: "Porque el 
alma tiene medios de comunicarse con ese más allá oculto, entre el microcosmo y el macrocosmo, entrambos espirituales en su esencia, existe un lenguaje común que les permite mostrarse el uno al otro y reconocerse: el idioma de los símbolos, de las metáforas y de las analogías" (20). Hay una paridad muy especial entre la poesía y el sortilegio, la poesía y el Shemá, quizá porque ambas dependen de la búsqueda del verbo original, el verbum dimissum.

Los poetas simbolistas nos enseñaron a percibir las analogías que reinan entre todas las cosas, con lo cual la ontología occidental es llevada o acercada a la poesía. Y, dado que se trata del símbolo y de la metáfora, y que el símbolo se comprende por una interpretación analógica y la metáfora es una de las formas de la analogía, la hermenéutica analógica es apropiada para este realismo poético que encontramos en la manera como los poetas simbolistas conjuntan la poesía con la ética y aun con la ontología; en el pensamiento hebreo el tema es más complejo, nos lleva hasta la fuente misma de la Creación y el Creador inmanente y trascendente en la expresión del amor humano (Tresmontant, Ensayo).

Es verdad que en la tradición Talmúdica la hermenéutica pretende llegar a devolver al texto sagrado la infinitud de interpretaciones, para devolver así a la divinidad el infinito que perdió al crear al hombre y su ser libre. Pero aun en ese caso el "Pardés" pone límites al quehacer de los interpretantes.

Podemos pensar en la multiplicidad como un ideal regulatorio para la experiencia amorosa, profundamente humana y divina al mismo tiempo.

La maravilla del Cantar quizás consista en posibilitar la doble aserción de R. Akiba y del Zohar, el Cantar es síntesis del todo de la experiencia humano-divina y en ello lo más cercano, en expresión mortal, al Santo de los Santos. 
Desde siempre, comentaristas judíos y cristianos, con motivos lo suficientemente oscuros como para que sea imposible el desciframiento total - aun para el más lúcido hermeneuta o el psicoanalista más experimentado- han dedicado sus mejores esfuerzos para prohibir la apreciación del placer expansivo de la pasión y el deseo de los enamorados del Cantar, y de todo ser humano (Ranke-Heinemann, Eunucos).

Sería muy larga, e incompleta, la lista de estos sabios, algunos de los cuales, en su momento, enfilaron sus baterías sobre fray Luis de León y su traducción del Cantar. Lo cierto es que conformaron una mentalidad descalificadora del amor humano; hoy participamos parcialmente en ese "imaginario social" que sesga nuestra lectura del texto en cuestión, aunque no lo queramos.

Aun cuando los especialistas en antropología bíblica, unidos a todos los demás estudiosos de la Escritura, insisten y coinciden en la valoración positiva de la sexualidad y el placer en la más representativa Tradición, es difícil sacudirnos la historia que cargamos y abrir los oídos a una escucha que tenga la misma libertad de goce que las expresiones de los amantes del Cantar, indisolublemente humano-divino.

\section{Invitación}

Pelletier, Casalis, Tournay, entre muchos otros comentaristas actuales, están de acuerdo en la necesidad de mantener una lectura múltiple, polisémica, del Cantar. Más allá de consideraciones, que fueron una vez y que aun hoy día son parcializantes si no reduccionistas hacia lo antropológico o angelista, se impone la polisemia. La iconicidad del Cantar permite retornar al plan original de la divinidad. Salta por encima de la desarmo- 
nía introducida por el así llamado "pecado original" a partir de Agustín de Hipona, establece una continuidad entre Génesis caps. 1 y 2, con el presente continuo del amor humano, cuyo fuego ardiente es como una llama divina, una llama de Yah (Cant. 8:6-7):

¡Graba mi nombre en tu corazón!

¡Graba mi imagen en tu brazo!

¡Tan fuerte es el amor

como la muerte!

¡Tan cierta es la pasión

como la tumba!

¡El fuego del amor es una llama

que Dios mismo ha encendido!

¡No hay mares que puedan

apagarlo,

ni ríos que puedan extinguirlo!

$\mathrm{Si}$ alguien se atreviera

A ofrecer todas sus riquezas

A cambio del amor, no recibiría más que desprecio.

(La Biblia. Traducción en lenguaje actual)

Šir ha Širim (El Cantar de los Cantares) más valioso que el universo...

\section{REFERENCIAS}

AAVV. Bible de Jerusalem; Nouvelle Edition, traduit en francais sous la direction de L'Ecole Biblique de Jerusalem, Paris, Cerf, 1998.

AAVV. Biblia de Jerusalén, trads. Edición española de la Biblia de Jerusalén, Bilbao, Desclée de Brower, 1998.

AAVV. La Biblia, Traducción en lenguaje actual con deuterocanónicos en orden alejandrino, Brasil, Sociedades Bíblicas Unidas, 2004. 
Baudelaire, Charles, "Correspondences". Poetry X. Les Fleurs $d u$ Mal. 〈http://poetry.poetryx.com/poems/1075/〉 [fecha de consulta: 24 de mayo 2010].

Blanco Beledo, Ricardo, "Mito e icono en la tradición judeocristiana", Tramas 13, 1999, 11-26.

Blanco Beledo, Ricardo, "Transicionalidad de lo imaginario en psicología y filosofía de la Religión”, en Espacios Imaginarios, María Noel Lapoujade (coord.), México, Universidad Nacional Autónoma de México, 1999, 121-131.

BlANCO BELEDO, Ricardo, "La violencia y lo sagrado en la tradición judeocristiana. Un enfoque psicoanalítico", Ponencia presentada en la Jornada Internacional sobre Religiosidad y Violencia, Buenos Aires, Universidad Católica Argentina, octubre 2005.

Blanco Beledo, Ricardo, "Sobre Hermenéutica, analogía, metáforas del significante y subjetividades contemporáneas", en Hermenéutica analógica en España, Joaquín Esteban Ortega (coord.), Valladolid, Universidad Europea Miguel de Cervantes, 2008, 31-42.

Brown, Raymond, Joseph FitzMayer y Roland Murphy, The Jerome Biblical Commentary, usA, Prentice Hall, 1968.

De la Torre Guerrero, Gonzalo M., El Amor, Fuego Divino... Introducción a la lectura del "Cantar de los Cantares", Colombia, Misioneros Claretianos, 1999.

Eslin, J. C. (coord.), La Bible 2000 ans de lectures, Paris, Desclee de Brower, 2003.

Gelin, Albert, L'homme selon la Bible, Paris, Ligel, 1962.

Grelot, Pierre, La pareja humana en la Sagrada Escritura, Madrid, Euramerica, 1963.

León, fray Luis de, Salomón, El Cantar de los Cantares, México, Espasa-Calpe, 1997 (Col. Austral, 464).

Lys, Daniel, "Ruach”, Le souffle dans L'Ancien Testament, Paris, Presses Universitaires de France, 1962.

Lys, Daniel, La chair dans L'Ancien Testament, Basar, Paris, Presses Universitaires de France, 1967. 
Mantilla Sahún, Roberto, El Placer en el Cantar de los Cantares, Vicisitudes de lo sublime, Tesis, México, Universidad Nacional Autónoma de México, Facultad de Filosofía y Letras, 2000.

Pelletier, Anne-Marie, El Cantar de los Cantares, Estella, Verbo Divino, 1995 (Cuadernos Bíblicos, 65).

Pfrimmer, Théo, Freud lecteur de la Bible, Paris, Presses Universitaires de France, 1982.

Quesnel, Michel y Philippe Gruson (dirs.), La Biblia y su cultura, trad. Ramón Alfonso Diéz Aragón, Santander, Sal Terrae, 2002.

Ranke-Heinemann, Uta, Eunucos por el Reino de los Cielos, Madrid, Trotta, 1994.

Raymond, M., De Baudelaire al surrealismo, México, Fondo de Cultura Económica, 1a. reimpr., 1983.

Schмid, Albert Marie, La literatura simbolista (1870-1900), Argentina, Eudeba, 1962.

SchöKel, Luis Alonso, El Cantar de los Cantares, Estella, Verbo Divino, 1990.

SchöKel, Luis Alonso, La Biblia del Peregrino, Biblia de Estudio, 3 vols, Estella, Verbo Divino, 1997.

Tournay, R. J., El Cantar de los Cantares, Madrid, FAX, 1970.

Tresmontant, Claude, Ensayo sobre el pensamiento hebreo, Madrid, Taurus, 1962.

Valle, Carlos del, La Mišna, Salamanca, Sígueme, 1997.

Wolf, Hans, Antropología del Antiguo Testamento, Salamanca, Sígueme, 1997. 